\title{
Smooth Running Without Power on Sole Hallucal Area
}

\author{
Mitsuru Murakami ${ }^{1}$ and Hiroshi Bando ${ }^{2,3 *}$ \\ ${ }^{1}$ Japan Masters Athletics, Kagawa division, Japan \\ ${ }^{2} J a p a n$ Masters Athletics, Tokushima division, Japan \\ ${ }^{3}$ Tokushima University / Medical Research, Japan \\ *Corresponding author: Hiroshi Bando, MD, PhD, FACP, Tokushima University /Medical Research, Nakashowa 1-61, Tokushima 770-0943, Japan
}

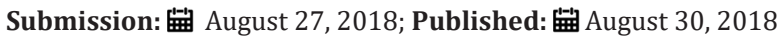

Keywords: Masters athletics; Japan masters athletics (JMA); Sole hallucal area; Thumball; The center of gravity; Flat grounding

\section{Commentary}

Humans are always performing various motion activities such as standing, walking, running and so on in their daily lives. Among them, if body movement becomes more reasonably, daily life will be more comfortable [1]. In this report, we focus on the foot/feet. The feet are usually in contact with the ground, supporting the whole body. In this case, how does the gravity center on the foot influence the movement of the body and other factors? [2] By analyzing based on the principle of lever, rational way of standing, walking and running would be considered. Furthermore, the authors have been engaged in sports medicine so far, and conducting physical research, especially on Masters Athletics [3,4]. We have also reported about the flexibility and psychological aspect of the spine that leads to better running $[5,6]$. All of these will lead to integrated improvement in performance.

Generally speaking, good attitude in standing was recognized to be 'upright standing immovable'. In this posture, we always open the toes bilaterally at an angle of 60 degrees, made the supporting area broader, place the center of the gravity a little nearer to toe and press the ground firmly. Then, tighten your buttocks, stretch your chest and pull your jaw downward to extend your spine. This posture was recommended and said to be necessary even in the sports. However, there is a problem with this previous posture. A man cannot keep the same posture for long due to persisting tension and tiredness [7]. In addition, the initiation of movement becomes delayed because the joints are fixed functionally [8]. Therefore, good posture would be proposed, which is easy and less tension or tiredness, smooth transition to the next movement, resulting in the functional superiority. In the following, three specific examples are described.

\section{Good posture in standing}

Currently, recommended good posture in standing exists where the center of gravity is below the tibia. A person can maintain the natural balance of the original skeleton and stand easily (Figure 1). On the sagittal plane anatomically, the outer malleolus, the greater trochanter, the shoulder peak and the ear hole are aligned on the center of the gravity line [9]. Consequently, the muscular tension and contraction necessary for controlling the balance is kept to minimum level [10]. Furthermore, as the inter-joint forces between the spinal column are aligned, the center axis of the body can be conscious. Then, the controllability of each part of the body increases, leading to the improvement of motor function.

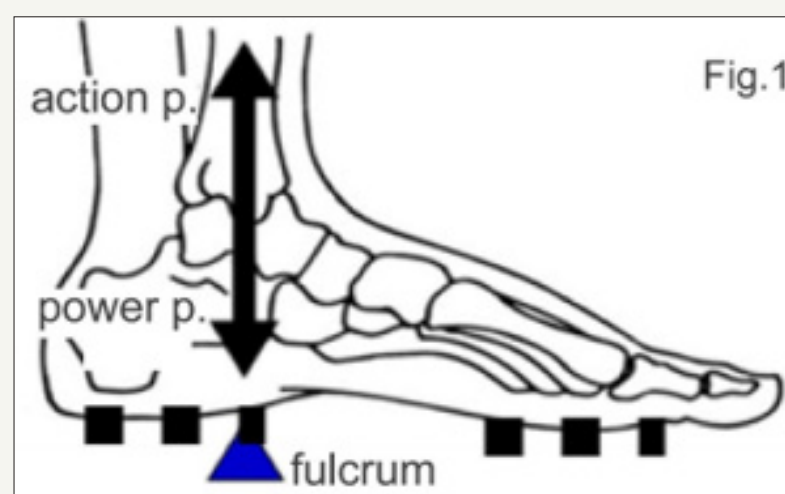

Figure 1: Standing posture with the center of the gravity below the tibia. The power point and the action point are on a line, with stability.

\section{Common posture in many people}

It is common in many people that the gravity center is situated at the foot in rather forward position (Figure 2). Then, in order to keep the posture constantly pressing the ground, posture holding muscles are always in tension. Furthermore, in the case of walking and running, a moment to the rear direction occurs at the time of grounding, so the body tends to return to the back. Contrary to this movement backward, it is very inefficient to force the body to move 
forward. As to grounding in this way, the quadriceps becomes main muscle to respond, without fully utilization of hamstring $[11,12]$ This is also a problem leading to fatigue and injury in rather strong loading. This tendency of forward balance is more common in Japanese. The reason is probably due to several factors, such as high heel shoes, crouching posture due to operation of personal computer and smart phone and emphasis on sole hallucal area (thumball, football) in the sports theory so far.

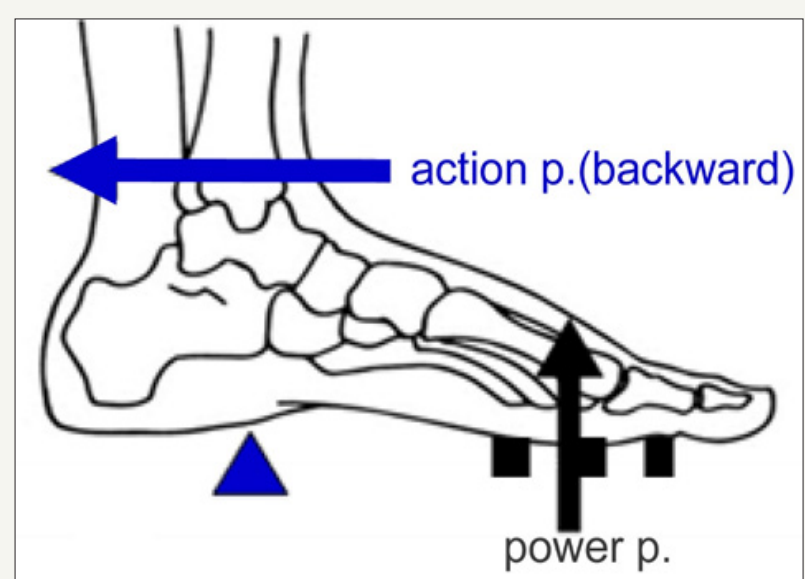

Figure 2: Starting of moving with the center of the gravity on the thumball. Due to upward of power point, action power becomes backward.

\section{Smooth running without power}

When the body is declined a little forward, the gravity center of the body is positioned somewhat forward from Figure1. (Figure 3) A person does not put the force on thumball [13]. In this position, a moment occurs collapsing forward and the body moves forward. For this kind of grounding method in walking and running, a person can feel that the body is pushed forward at the heel as a fulcrum, and that the center of gravity is moving forward smoothly. That crucial point is not to put the force in thumball, or not step on, but to use the entire sole of the foot to make a soft and flat ground. Hamstring can be used sufficiently by flat grounding, leading to less injury or less fatigue.

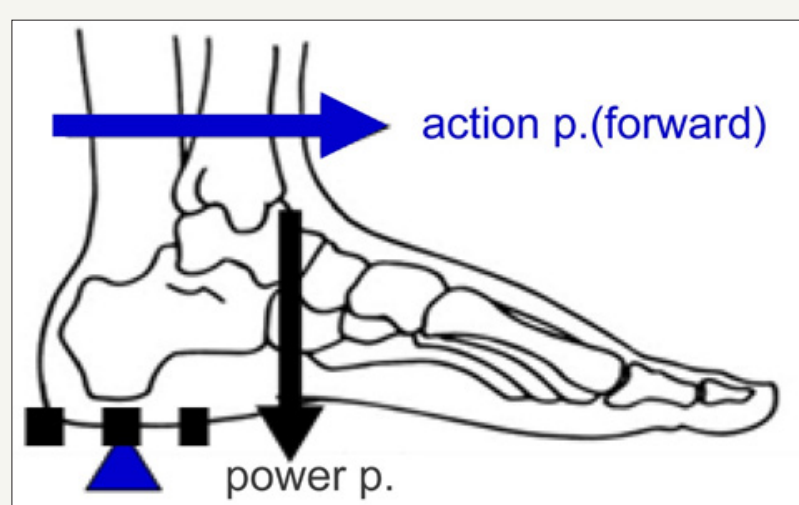

Figure 3: Starting of moving with gravity center below the tibia, without force on the thumball. Due to downward of power point, action power becomes forward.
Authors have advised many players through textbook, seminar and workshop as the Japan Masters Athletics (JMA) [14]. The goal is that Masters can continue to run happily without hurting. The actual method is to give them basal knowledge, practice and experience concerning how to run fast and safe. As an effect, long distance runners have already certain effect of better running form, extending the record and reducing the breakdown or injury. On the other hand, short distance players have used to previous running style, and it is not easy to change the way with relax [15]. However, authors can run with flat grounding, then we can explain the tips with no injury for them.

In summary, it is important to understand the motion mechanism including the center of gravity of the body when a person walks or runs. As players run in better way with flat ground, he has better performance and less injury. Its effect has been already found in long distance players leading to happier life [16]. Consequently, our future tasks are the management for short distance players. The authors wish to continue practice, research, and guidance concerning this field in the future.

\section{References}

1. Murakami M (2016) Physical motion and care in integrative medicine. J Integr Med Jap Shikoku Div 9: 3-5.

2. Bando H, YoshiokaT, Yonei Y, Nakamura T (2006) Investigation of quality life in athletes from an anti-aging perspective. Primary Care Japan 4(1): 47-51.

3. Murakami M (2017) How to run for masters athletes without injuryNatural run with usage of gravity and reflex. Kagawa Exercise Bulletin $3: 45-48$.

4. Bando H, Nakamura T, Yonie Y, Takenaka Y, Seki K (2015) Lipid profile of masters athletes in ice-skating, a model of anti-aging research. Glycat Stress Res 2(2): 52-57.

5. Moriyasu A, Bando H, Akayama R, Wakimoto K, Dakeshita T, et al. (2017) Thorax flexibility can be increased by standing pole exercise. Int J Phys Med Rehabil 6: 444

6. Bando H, Takenaka Y, Nakamura T, Kounoike K, Yonei Y (2015) Investigation for Quality of Life (QOL) and self-esteem for health in masters' athletes. Glycat Stress Res 2 (4): 174-181.

7. Hoffman J, Gabel P (2013) Expanding panjabi's stability model to express movement: A theoretical model. Medical Hypotheses 80(6): 692-697.

8. Izzo R, Guarnieri G, Guglielmi G, Muto M (2012) Biomechanics of the spine. Part I: Spinal stability. Euro J Radiol 82(1): 127-138.

9. Danis CR, Krebs DE, Gill-Body KM, Sahrmann S (1998) Relationship between standing posture and stability. Physical Ther 78(5): 502-517.

10. Gantar S (2016) Differences in postural activity during quiet standing when breathing abdominally. Charles University, Prague.

11. Bruno P (2014) The use of "stabilization exercises" to affect neuromuscular control in the lumbopelvic region: a narrative review. J Can Chiropr Assoc 58(2): 119-130.

12. Wakimoto K, Dakeshita T, Tatejima T (2011) Comparison of curved angles in spinal alignment between patients with chronic pain disease and physically unimpaired persons. Int Society Biomechanics.

13. Shu Y, Mei Q, Fernandez J, Li Z, Feng N, Gu Y (2015) Foot morphological difference between habitually shod and unshod runners. PLoS ONE 10 (7): e0131385. 
14. Murakami M, Bando H (2018) Crucial point of how to run in the seminar and workshop in 2017 -tips for natural way of running without injury. Investigation of masters' athletes. Annual report of Japan Masters Athletics Association 36: 21-22.

15. Moriyasu A, Bando H, Murakami M, Inoue T, Taichi A, et al. (2018) Pole exercise causes body changes in physical flexibility and exercise function. J Nov Physiother 8(1): 377.
16. Bando H (2018) Lifestyle intervention and weight reduction for obese elderly as to flailty and sarcopenia. J Nov Physiother 8(3): e152.
(C) (i) Creative Commons Attribution 4.0

For possible submissions Click Here
Submit Article

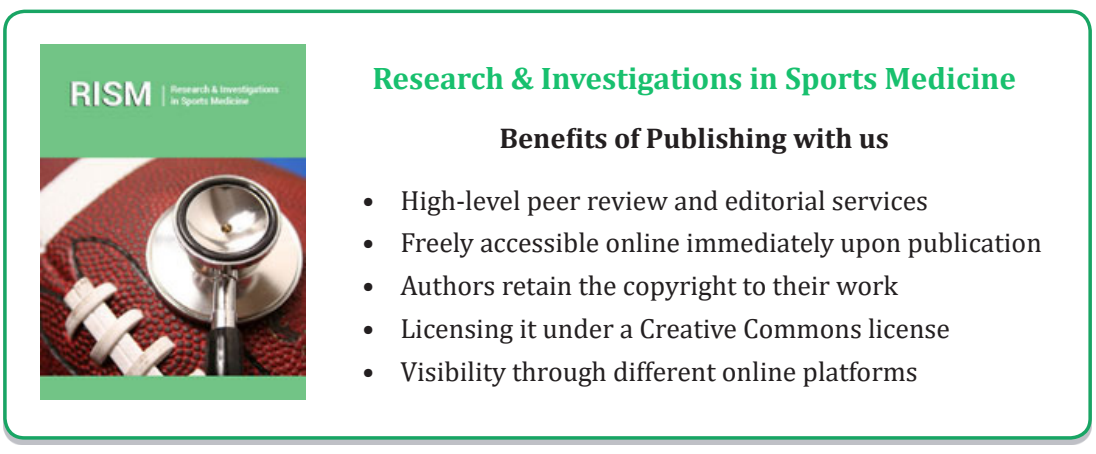

